\section{EL PROYECTO DE INVESTIGACIÓN PARA EL ESTUDIO DE LA GEOMETRÍA DENTRO DE LA REALIDAD ARQUITECTÓNICA. EL TRABAJO POR PROYECTOS}

\author{
A. Moratalla, J. M. Sánchez \\ Departamento de Matemática Aplicada a la Edificación \\ Medio Ambiente y Urbanismo, UPM, Juan de Herrera 4 \\ ascension.moratalla.delahoz@upm.es y juanamaria.sanchez@upm.es

\section{Moratalla} \\ Departamento de Orientación del C. Ntra. Sra. De Loreto, \\ O'Donnell 61 \\ orientacion@realcolegioloreto.com \\ M. A. Sanz \\ Departamento de Matemática e Informática Aplicada a la Ingeniería \\ Civil, UPM, José Aranguren s/n \\ mariaagripina.sanz@upm.es
}

ABSTRACT: The PBL is a very suitable methodology for being used in the University teaching, because of is researcher character. The learning is active, it involves all the students and works other different cognitive capabilities that where developed with the master class. In this course, with the implementation of Bologna Plan, we plan, with some other teachers who belong to the educational innovative group Didáctica de las Matemáticas, at the UPM, to introduce some changes aimed at this type of learning in the subject of the first Degree course of Architecture, called Geometría Euclidea, Afin y Proyectiva (Euclidean geometry, Affine and Projective).

KEY WORDS: PBL; innovation; geometry; architecture.

1. INTRODUCCIÓN

El aprendizaje basado en proyectos surge de la necesidad de plantear un nuevo paradigma educativo donde el protagonista sea el alumno. Esta propuesta de trabajo influye sustancialmente en los roles del profesor y del estudiante, estableciendo una dinámica distinta en el proceso de aprender y de enseñar.

Como indica Colen, Gine e Imbernon (2006), el alumno aprende: De una manera más activa ya que parte de una
THE RESEARCHING PROJECT FOR THE STUDY OF GEOMETRY IN THE ARCHITECTONICAL REALITY. PBL
RESUMEN: El Trabajo por Proyectos es una metodología muy apropiada para utilizarla en la enseñanza superior, por su carácter investigador. El aprendizaje es activo, involucra al alumno y trabaja otras capacidades cognitivas distintas a las que se desarrollan con la clase magistral. Con la implantación, este curso, del llamado Plan Bolonia, algunos profesores pertenecientes al Grupo de Innovación Educativa Didáctica de las Matemáticas de la UPM, nos planteamos introducir en la asignatura de primer curso del Grado de Arquitectura, denominada Geometría Euclídea, Afín y Proyectiva algunos cambios dirigidos a este tipo de aprendizaje.

PALABRAS CLAVE: Trabajo por proyectos; innovación; geometria; arquitectura.

propuesta de trabajo y, sobre ella, debe buscar y organizar una información que no le ha sido dada aunque si sugerida; poniendo en funcionamiento unas capacidades intelectuales distintas a las que viene utilizando en una clase magistral, basada en el hecho de: escucho y apunto; a trabajar en equipo, siendo parte responsable de la óptima consecución del trabajo y desarrollando habilidades de tipo emocionales; partiendo de cuestiones, planes o problemas conectados con la realidad; buscando, indagando, preguntando, formulando... y, para ello, utilizando todos los medios TIC a su alcance; defendiendo su proyecto ante pro- 
fesores y compañeros, dos tipos de oyentes muy distintos ante los que exponer sus soluciones razonadas; teniendo la oportunidad de aportar creatividad y autonomía en su trabajo y, por lo tanto, aumentando su motivación.

El profesor enseña: Orientando el trabajo, y para ello plantea preguntas, indica sobre materiales y medios a utilizar, propone ejemplos y reconduce objetivos; incitando a debates sobre los temas elegidos en los que se discute sobre los resultados obtenidos, y los procesos seguidos; asesorando sobre la aplicabilidad del proyecto; ideando nuevas formas de evaluación para nuevas formas de aprendizaje.

Adecuándose a las necesidades reales de la sociedad en cada tema de trabajo y haciendo partícipe de sus reflexiones al alumnado: La planificación del trabajo y del tiempo es esencial para llevarlo a buen fin (este sería un punto desarrollar por el profesor); el esfuerzo hay que realizarlo día a día, ya que no es posible llevar a cabo una labor en equipo, planteada en el tiempo, poco antes de una entrega o de un examen (labor del alumnado); la importancia de la tutoría como método de trabajo alumnos-profesor; el conocimiento de las fuentes de información y el suficiente dominio de las herramientas tecnológicas necesarias para desarrollar estos proyectos y la hetero-evaluación es continua y significativa, ya que, para superar la asignatura, no se depende de un único examen.

Como consecuencia de todas estas reflexiones, en el Grupo de Innovación Educativa Didáctica de las Matemáticas, estudiamos la posibilidad de realizar, en la asignatura de primer curso del Grado de Arquitectura denominada Geometria Euclídea, Afín y Proyectiva, algunos cambios dirigidos a la parcial introducción de este tipo de aprendizaje.

\section{Objetivos}

El objetivo general de esta acción es conseguir que el alumno esté más motivado por su trabajo y por tanto mejore su rendimiento. Para ello se propone introducir una nueva metodología de enseñanza-aprendizaje en la asignatura de Geometría del primer cuatrimestre, que vaya acompañada de los cambios consiguientes en el tipo de evaluación.

ARBOR Vol. 187 Extra 3 diciembre [2011] 219-224 ISSN: 0210-1963
Para alcanzar este objetivo tendremos que ir consiguiendo otros objetivos más específicos como son: Centrar la metodología en el alumno potenciando la relación alumno-profesor; alcanzar un conocimiento multidisciplinar; desarrollar la capacidad de análisis del alumnado e iniciar a los alumnos de nuevo ingreso en la investigación científica y en el necesario manejo de fuentes de información fiables.

\section{Desarrollo}

A lo largo de nuestra dilatada labor como profesores de Matemáticas en la Universidad Politécnica de Madrid, ya habíamos venido experimentando anteriormente con este tipo de enseñanza, animados por autores como Alsina, Burgués y Fortuny (1997).

En los cursos del plan anterior al de Bolonia, los trabajos se proponían como voluntarios para los alumnos y estaban más enfocados al estudio de una Geometría Analítica, a la que se trataba de buscar conexiones con los conocimientos aportados en las distintas asignaturas de Dibujo que cursaban paralelamente. Como los estudiantes no eran muchos, las conversaciones eran frecuentes y así llegamos al conocimiento de que, lo que realmente les atraía, era la obra final, el edificio que podian percibir en su entorno capaz de generar ciudad, el saber a donde les conducía el estudio de unos conceptos a los que no se les veía, en principio, la aplicación concreta que podían tener en su formación y posterior actividad como arquitectos.

Con estas premisas, el camino que seguimos para el desarrollo de esta experiencia comienza ya en la presentación de la asignatura a comienzos de curso. Junto al contenido del Programa y el resto de normas que van a regir durante el período lectivo, se hace un recorrido por los distintos tipos de geometrías con las que se van a encontrar, resaltando cómo esos principios geométricos pueden influir en el hecho arquitectónico. A continuación se propone al alumnado la posibilidad de conseguir una parte de su nota final mediante la elaboración de un trabajo consistente en el estudio de una obra de arquitectura que se pueda relacionar con alguna de las geometrías que se abordarán. En horas de tutela dentro del aula, se tutoriza el trabajo, que 
se puede llevar a cabo en forma individual o en pequeños grupos, no más de tres alumnos. Para su evaluación, se deberá presentar el estudio realizado en un formato predeterminado pudiendo, además, ser expuesto en clase para su general conocimiento.

Con el fin de demostrar el grado de implicación de los alumnos en este tipo de trabajos, aportamos algunas imágenes de los realizados, tanto por los alumnos de nuevo ingreso, como por los distintos grupos que nos han servido de ensayo previo a esta experiencia.

\section{A. Alumnado de Primer Curso}

Este trabajo ha sido llevado a cabo por los alumnos Ismael Carpio y Leila Eetesam. Las imágenes son fragmentos de un estudio que se presentó en formato póster.

Anteriormente nos hemos referido al hecho de que, desde el inicio de curso, comenzamos a conectar la Geometría con el diseño y el resultado final de una obra de arquitectura, resaltando cómo los principios matemáticos pueden influir en su aspecto y cómo, en múltiples ocasiones, la obra de arte se puede relacionar con alguna de las geometrias planteadas en el curso.

A este nivel los trabajos son elementales y se basan en el análisis geométrico en una determinada obra de arte. Una vez reconocida la composición base de la imagen arquitectónica se elabora un programa, sencillo, de ordenador capaz de generar la geometría correspondiente (fig. 1).

\section{B. Alumnos con Becas de Excelencia}

Una parte importante de la evolución del planteamiento de esta propuesta, se desarrolló con la dirección de trabajos de investigación de estudiantes con Becas de Excelencia de la Comunidad de Madrid. A estos alumnos se les permitía elegir, entre las propuestas de los distintos Departamentos de la Escuela Técnica Superior de Arquitectura de Madrid. Debian cumplir cincuenta horas de colaboración o investigación exigidas para la consecución de la Beca. Nuestra opción, desde el Departamento de Matemáticas, consistía en la elaboración de un trabajo de investigación, debidamente dirigido, en el que confluian conocimientos de Historia, Geometría y Dibujo que, una vez concluido servía de base al alumno para sacar conclusiones de su experiencia. En los últimos cinco años nuestro GIE se ha hecho cargo de al menos 50 de estos alumnos.

En este caso ya se les exige la coordinación de las distintas facetas que pueden confluir en el ejercicio: Geometría, Cálculo, Diseño o Historia (fig. 2).

\section{Alumnos de Asignatura de Libre Elección (Plan 96)}

Una fuente decisiva de contraste, en el sentido de valorar el interés de los estudiante por conocer la influencia y la importancia de la Geometría en las distintas etapas históricas vividas por la Arquitectura, ha sido el seguimiento de la Asignatura de Libre Elección "Análisis y Reconocimiento de la Geometría en la Arquitectura de las Vanguardias",
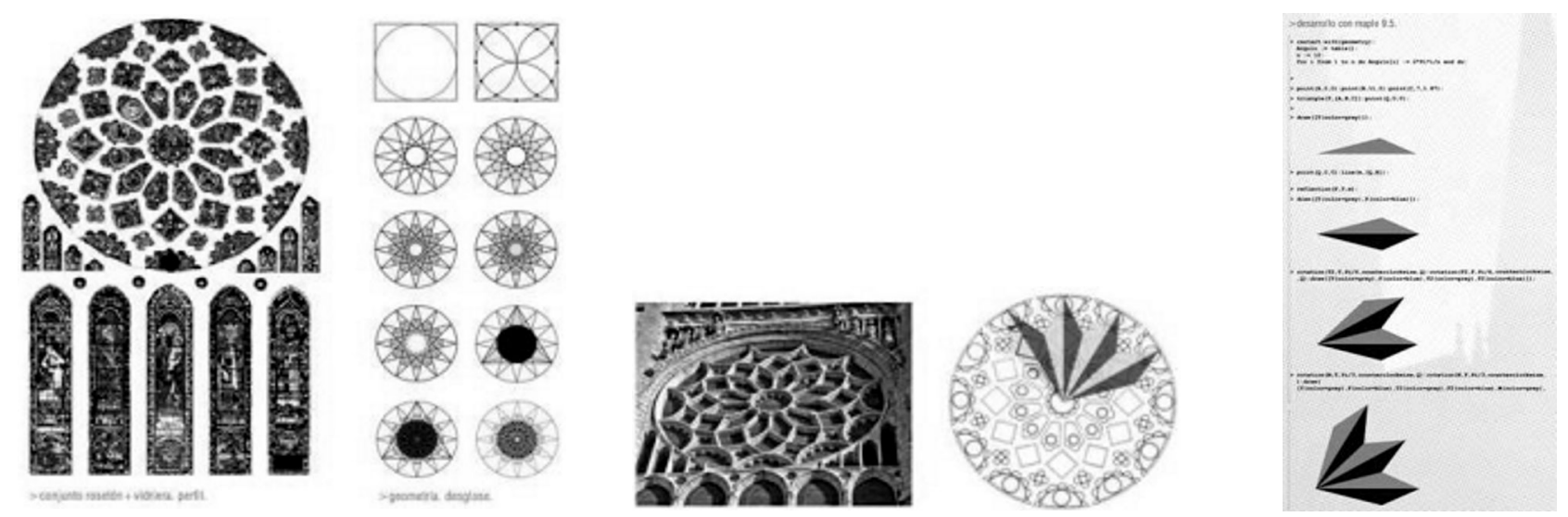

Figura 1. Rosetón de la Catedral de Chartres y su trazado geométrico. Programa informático. 

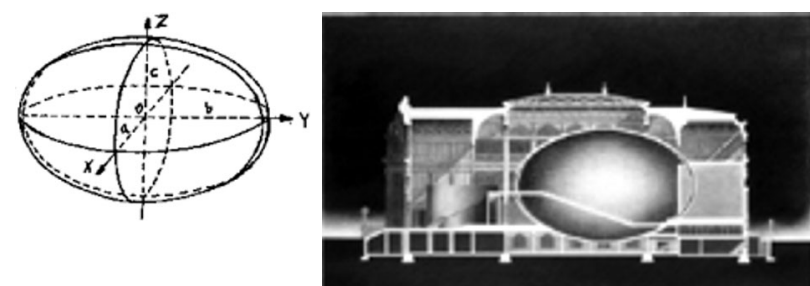

Figura 2. Imagen de un elipsoide genérico y sección vertical del proyecto en Nakanoshima (Urban Egg, 1988) de Tadao Ando.

impartida por la profesora del GIE Juana María Sánchez, en la que se lleva a cabo un estudio teórico y práctico sobre las relaciones existentes entre modelos matemáticos y obras de arquitectura. El alumnado, para seguirla, una vez tenga superadas las asignaturas previas de Matemáticas, puede pertenecer, indistintamente a cualquier nivel dentro de la carrera de Arquitectura, a otros centros de la UPM o proceder de cualquier universidad con la que se tengan intercambio de cualquier tipo.

El hecho de que el grupo pueda presentar una gran heterogeneidad de formación y de nivel académico, enriquece el proceso y hace que los trabajos a desarrollar tengan una gran variedad, y se puedan acometer estudios en los que, además de la Geometría y la Arquitectura, aparezcan otros temas relacionados con ellas.

La docencia se desarrolla mediante lecciones teóricas acompañadas de trabajos prácticos en los que se analizaran fundamentalmente ejemplos contemporáneos.
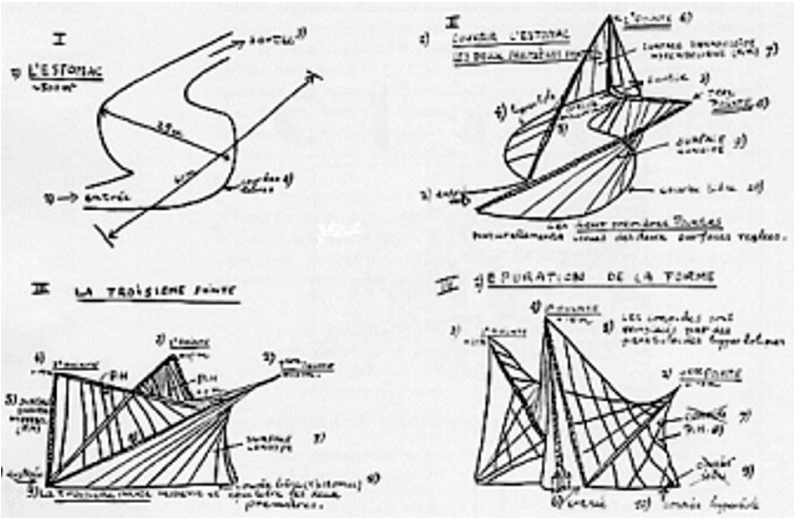

Las imágenes que ilustran este apartado pertenecen al estudio "Arquitectura Sonora Música Habitable" Ilevado a cabo por Enrique Ruiz Pascual, estudiante de Arquitectura, en el segundo cuatrimestre de 2010.

El punto de partida fue el Pabellón Philips, obra en la que se mezclaron la Arquitectura, la Música y la Poesía de la mano de sus autores: Le Corbusier, no sólo arquitecto; lannis Xenakis, no sólo músico y de Edgar Varese, autor del Poema Electrónico que se reproducía en el Pabellón durante su visita.

El resultado académico fue un estudio en el que, partiendo del supuesto de que todas las bellas artes están ligadas entre sí de alguna manera, y teniendo como primera intención el análisis de la geometría que configuraba el pabellón (fig. 3) construido, en 1958 para representar a la marca en la Exposición de Bruselas, mediante el uso de programas informáticos (fig. 4) (fig. 5) y (fig. 6) se llegó a descubrir cómo y hasta que punto, una música puede dar vida a una arquitectura $y_{\text {, }}$ como consecuencia, intentar plantear la posibilidad de que una arquitectura pudiese dar vida a una pieza musical.

En las figuras siguientes se distingue entre las que formaron parte de las fuentes utilizadas y las realizadas por el alumno.

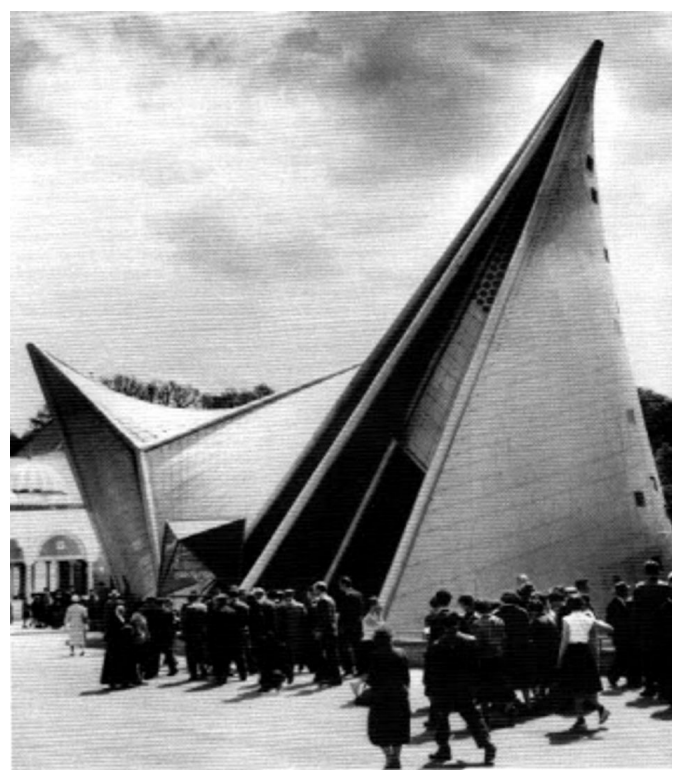

Figura 3. Datos de partida: Croquis para el pabellón Philips (1958), Pabellón Philips. Le Corbusier-Xenakis. 

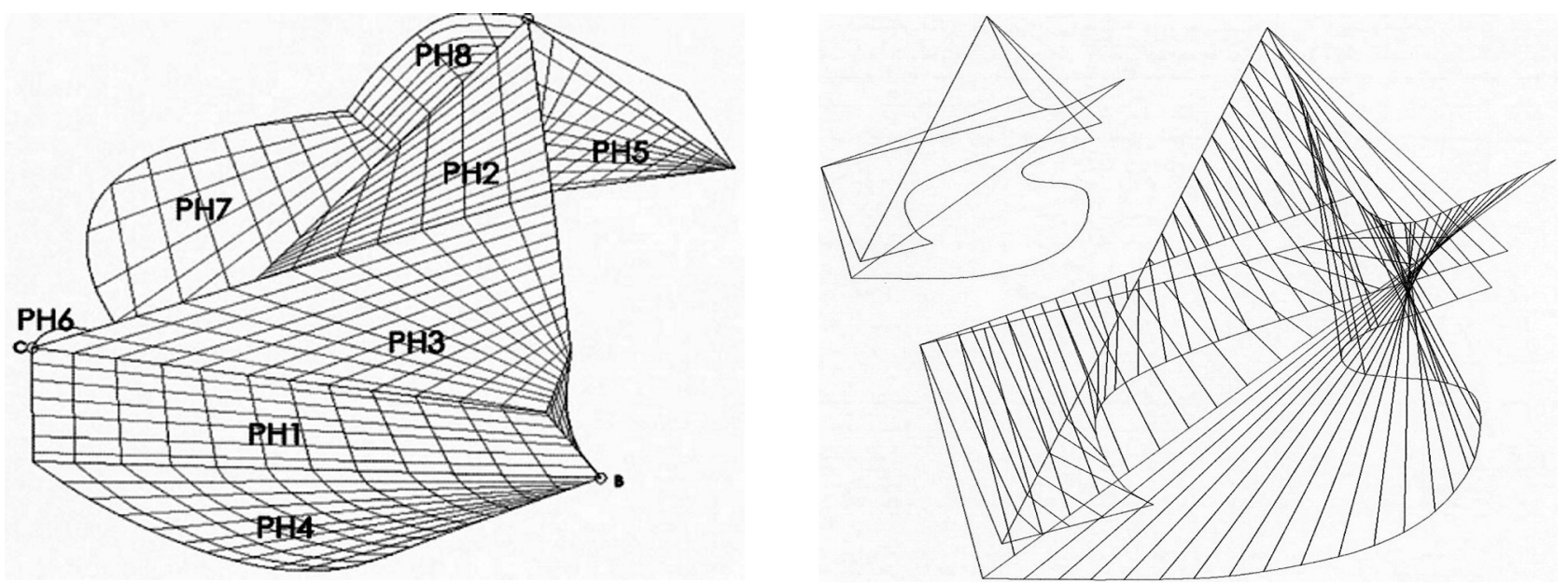

Figura 4. Descomposición informática de las distintas superficies que intervienen en el diseño del pabellón Philips.
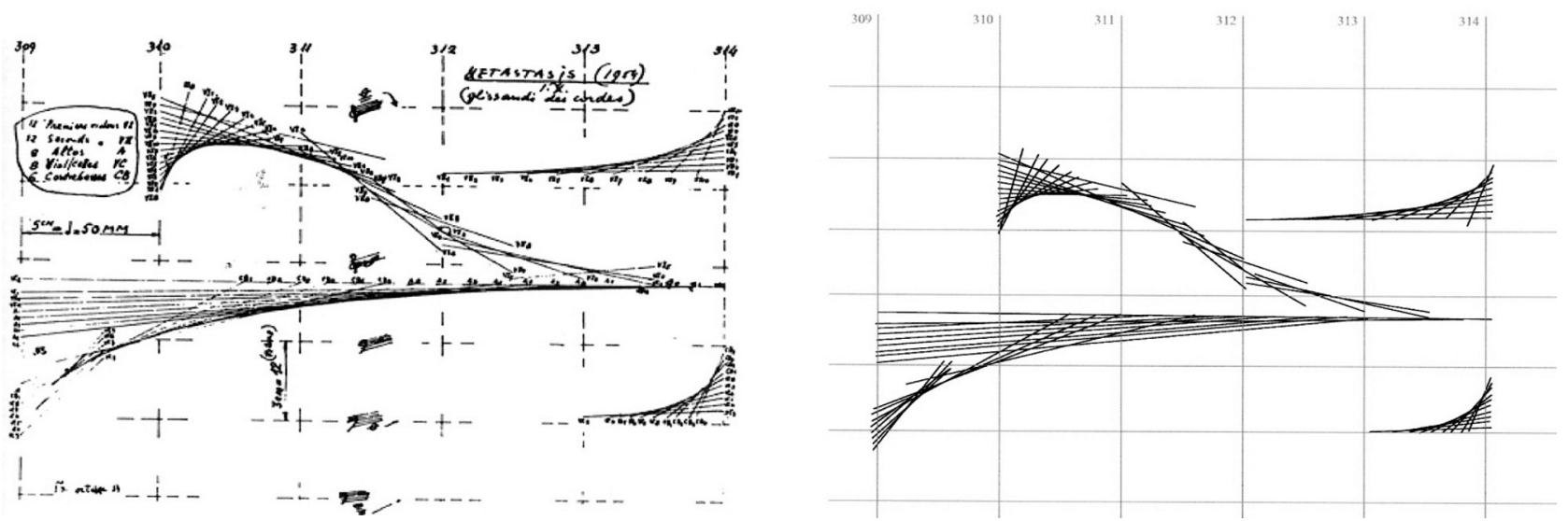

Figura 5. Datos de partida: Primeras anotaciones de la partitura Metástasis (Xenakis, 1954), su recreación informática.

\section{Conclusiones}

Creemos que las conclusiones deben ser presentadas haciendo alusión previa a las experiencias didácticas que motivaron esta iniciativa de plantear una forma nueva de aprendizaje, desde una asignatura de Matemáticas, en los alumnos de primer curso de Arquitectura.

Conscientes del resultado obtenido en los cursos anteriores al Plan de Bolonia, en los Trabajos de Excelencia en los que participaron, de forma voluntaria, los alumnos con mejores expedientes de una carrera en la que la nota de corte es de las más altas de la Universidad Madrileña, y en los llevados a cabo en el marco de la Asignatura de Libre Elección, todavía vigente, que permite la posibilidad de conocer trabajos de investigación llevados a cabo por personas de distinto nivel académico o procedentes de distintas carreras técnicas e, incluso, de planes de estudio vigentes en países distintos del nuestro; el observar la satisfacción, y en muchos casos la sorpresa que producía el descubrir 


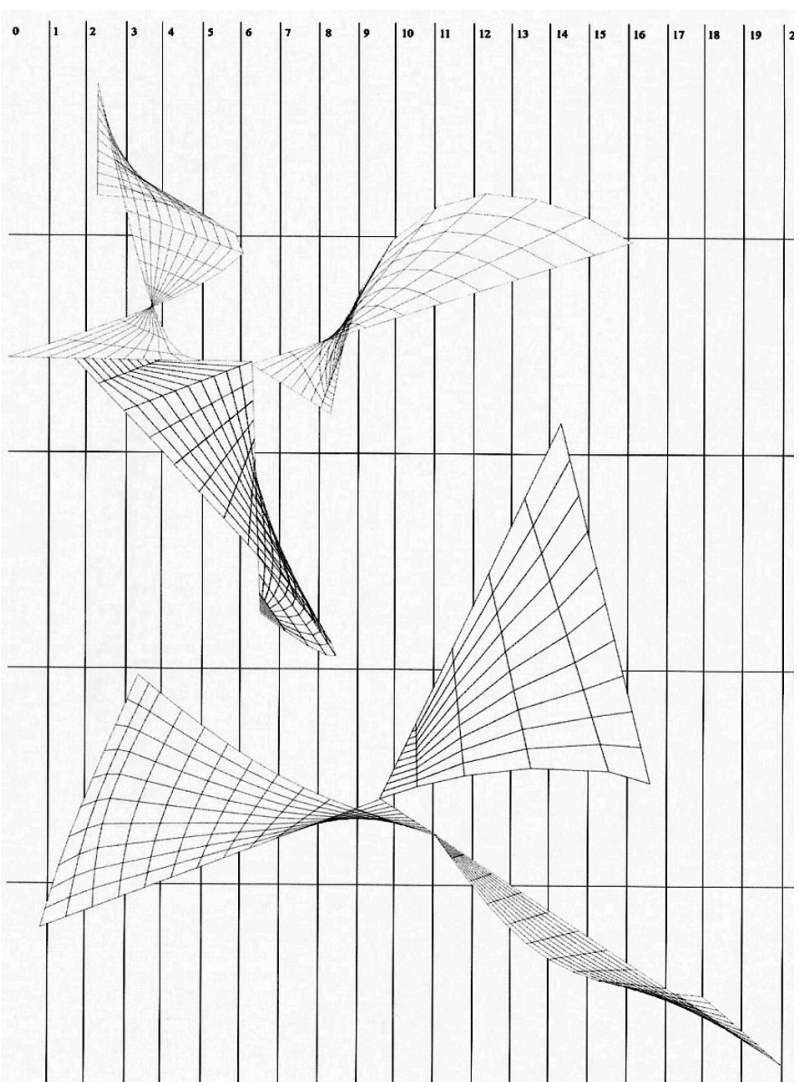

Figura 6. Partitura creada siguiendo las pautas de la compuesta por Xenakis, utilizando fragmentos de paraboloides. lo presente que estuvo la formación geométrica de sus autores en muchos de los proyectos que llevaron a cabo, propició la idea de plasmar esta faceta de la Geometría desde el Trabajo por Proyectos.

Así, desde el comienzo de su formación como arquitectos, los alumnos de Primero, en su primer cuatrimestre, toman contacto, simultáneamente, con unos conocimientos teóricos, continuación de los presentes en el Bachillerato, y con las imágenes arquitectónicas a las que han servido de base o de inspiración a lo largo de toda la Historia de la Arquitectura. Trabajos que ya hemos llevado a cabo en distintos cursos académicos en esta línea, se pueden consultar en las referencias Ruiz y Sánchez (2007), Sanz y Moratalla (1998), Sanz y Moratalla (1999), y Moratalla y Sanz (2000).

A pesar del escaso peso que supone la nota adjudicada a un trabajo que conlleva dedicación y consume tiempo, la implicación de los alumnos ha sido muy alta y ha tenido una repercusión positiva en los resultados globales de la asignatura. Asimismo los alumnos que han seguido esta metodología, han afrontado el resto de las asignaturas, las centradas en el dibujo y el análisis de la obra arquitectónica, con el valor añadido de reconocer la geometría que la sustenta.

\section{BIBLIOGRAFÍA}

Alsina, C.; Burgués, C. y Fortuny, J. M. (1997); Invitación a la didáctica de la Geometría, Editorial Síntesis Madrid.

Colen, M. T.; Gine, M. e Imbernon, F. (2006): La carpeta de aprendizaje del alumnado universitario, Editorial Octaedro, Barcelona.

Moratalla, A. y Sanz, M. A. (2000): Proporción. Serie Geometría y Arquitectura III. Cuadernos de Apoyo a la Docencia del Instituto Juan de Herrera, Publicaciones de la Escuela Superior de Arquitectura de Madrid, Madrid.
Ruiz, F. y Sánchez, J. (2007): La Espiral en la Arquitectura: Espacios pictóricos y arquitectura, Editorial Mairea, Madrid.

Sanz, M. A. y Moratalla, A. (1998): Geometría en la Arquitectura. Serie Geometría y Arquitectura I, Cuadernos de Apoyo a la Docencia del Instituto Juan de Herrera, Publicaciones de la Escuela Superior de Arquitectura de Madrid, Madrid.

Sanz, M. A. y Moratalla, A. (1999): Simetría. Serie Geometría y Arquitectura II, Cuadernos de Apoyo a la Docencia del Instituto Juan de Herrera, Publicaciones de la Escuela Superior de Arquitectura de Madrid, Madrid. 